First publ. in: Journal of Immunological Methods 270 (2002), 1, pp. 11-18

\title{
Purification and characterization of soluble CD21 from human plasma by affinity chromatography and density gradient centrifugation
}

\author{
Madhan Masilamani ${ }^{\mathrm{a}}$, Hans-Jürgen Apell ${ }^{\mathrm{b}}$, Harald Illges ${ }^{\mathrm{a}, \mathrm{c}, *}$ \\ a Immunology, Department of Biology, Faculty of Sciences, University of Konstanz, M662, D-78457 Konstanz, Germany \\ ${ }^{\mathrm{b}}$ Biophysics, Department of Biology, Faculty of Sciences, University of Konstanz, M662, D-78457 Konstanz, Germany \\ ${ }^{\mathrm{c}}$ Biotechnology Institute Thurgau, Konstanzerstr. 19, 8274 Tägerwilen, Switzerland
}

\begin{abstract}
Complement receptor II (CD21) is the receptor for C3d fragments on immune complexes. It also serves as a receptor for Epstein-Barr virus (EBV) and on B-lymphocytes CD21 amplifies signalling through the B cell receptor. CD21 is shed from the surface of the cell and is found circulating in plasma. There, soluble CD21 (sCD21) binds to CD23 and complement fragments, thereby modulating the immune response. $\mathrm{SCD} 21$ activates monocytes through binding to membrane $\mathrm{CD} 23$. The clinical significance of SCD21 is shown by the increased levels found in the sera of patients with B lymphomas, EBV infections and other lymphoblastoid tumors. In this paper, we report the isolation of soluble CD21 from human plasma using affinity chromatography and density gradient centrifugation. sCD21 was found to be a single $126 \mathrm{kDa}$ molecular species. By determining the sedimentation coefficient, we have calculated the partial specific volume, diffusion coefficient and frictional coefficient of the protein. These values show that the $\mathrm{sCD} 21$ isolated from human plasma is an elongated rod-shaped molecule.
\end{abstract}

\section{Introduction}

The complement receptor type II (CD21) belongs to the super gene family of regulators of complement activation. $\mathrm{CD} 21$ is the functional receptor for $\mathrm{C} 3 \mathrm{~d}$

* Corresponding author. Immunology, Department of Biology, Faculty of Sciences, University of Konstanz, M662, D-78457 Konstanz, Germany. Tel.: +49-7531-882255; fax: +49-7531-883102.

E-mail address: harald.illges@uni-konstanz.de (H. Illges). fragments on immune complexes and the EpsteinBarr virus (EBV) envelope protein gp350 (Ahearn and Fearon, 1989; Tsoukas and Lambris, 1993). This 140 $\mathrm{kDa}$ glycoprotein consists of 15 or 16 extracellular short consensus repeats of $60-70$ amino acids each and a short cytoplasmic sequence of 34 amino acids (Iida et al., 1983; Weis et al., 1984). CD21 is expressed on mature B-lymphocytes, B cell lines, but not on early pre-B cell and late developmental stages (Tedder et al., 1984). In addition, it is also expressed on peripheral blood and thymic $\mathrm{T}$ cells (Fischer et al., 1991), T cell lines (Larcher et al., 
1990; Delibrias et al., 1992) and a number of other cell types (Fearon, 2000).

Functionally, CD21 on B cells and follicular dendritic cells (FDC) is implicated in the recognition and binding of immune complexes, whereas its function on $\mathrm{T}$ cells and all other cell types is not known. In T cells, the expression of $\mathrm{CD} 21$ is developmentally regulated as double negative thymocytes express membrane bound CD21 (Fischer et al., 1999). On mature B cells, CD21 forms a noncovalent signal transduction complex in the plasma membrane together with CD81, Leu13 and the pan-B cell antigen CD19. This complex amplifies the signal transmitted through the B cell receptor by specific antigen and thereby reduces the threshold of antigen necessary to initiate cell proliferation (Dempsey et al., 1996; Cherukuri et al., 2001). In human pro- and pre-B cells, the expression of the CD21 gene is silenced by methylation of a $\mathrm{CpG}$ island in its promoter. Expression in mature $\mathrm{B}$ cells is accompanied by the loss of $\mathrm{CpG}$ methylation (Schwab and Illges, 2001a,b).

CD21 is also found in a soluble form (sCD21) generated by shedding from lymphocytes in culture and in human plasma (Myones and Ross, 1987; Ling et al., 1991; Huemer et al., 1993). Ling et al. (1991) has purified a 72-kDa form of sCD21 from lymphoblastoid cell lines by affinity chromatography on Sepharose-coupled BU34, BU33 and BU36 mAbs followed by DEAE ion exchange chromatography. Later, by metabolically labeling the LICR-LONHmy cell line with $\mathrm{S}^{35}$, these authors were able to isolate several proteins having molecular weight in the range $30-130 \mathrm{kDa}$. In addition to various proteins isolated from tissue culture supernatants, cell-associated CD21 from cell lysates was detected as a 120$140-\mathrm{kDa}$ molecule and was shown to be reduced to $115 \mathrm{kDa}$ upon treatment with endoglycosidase (Ling and Brown, 1992). sCD21 affinity-purified from human serum with THB5 and BU32 mAbs showed a $135-$ and $90-\mathrm{kDa}$ protein. Moreover, sCD21 circulates as a complex with cleavage fragments of $\mathrm{C} 3$ and a trimeric form of soluble CD23 (sCD23). CD21 isolated from human serum showed a smear of $135-190 \mathrm{kDa}$ under nonreducing conditions (Fremeaux-Bacchi et al., 1998b).

There are reports of a clinical association between the presence of $\mathrm{sCD} 21$ in plasma and $\mathrm{B}$ cell chronic lymphocytic leukemia (B-CLL), common variable immunodeficiency (CVID) and Brutons's X-lined agammaglobulinemia (Lowe et al., 1989; Ling et al., 1991). Elevated levels of sCD21 were found in patients with EBV-associated malignancies (Huemer et al., 1993). An as yet unknown protease is thought to be responsible for the shedding of CD21 from the membrane. In order to define biochemically the recognition site of the protease, design sensitive assays such as ELISA and to undertake other biophysical studies which require higher degree of purity, it is important to purify to homogeneity sCD21 from human serum. Here, we report the purification of soluble CD21 in its monomeric form from human plasma using affinity chromatography and density gradient centrifugation. Affinity chromatography employing antibodies to different epitopes of CD21 co-purifies other proteins, as would be expected. Upon high-speed density gradient centrifugation, we were able to isolate pure sCD21 with a molecular weight of about $126 \mathrm{kDa}$. We also report the sedimentation coefficient of the protein, biophysical parameters and its mobility in reducing/nonreducing SDS-PAGE and immunoblotting compared to cellular CD21 isolated from B and T cell lines.

\section{Materials and methods}

\subsection{Human plasma, cells, antibodies and reagents}

Human plasma was collected from healthy blood donors. The mature human Raji B cell line (Klein et al., 1975) and the Molt-4 T cell line (Minowada et al., 1972) were grown in Iscove's DMEM medium (Invitrogen, Karlsruhe, Germany) supplemented with $10 \%$ FCS, $1000 \mathrm{U} / \mathrm{ml}$ penicillin and $100 \mu \mathrm{g} / \mathrm{ml}$ streptomycin at $37{ }^{\circ} \mathrm{C}$ in $7.5 \% \mathrm{CO}_{2}$. Monoclonal anti-CD21 antibody clones BU32 (IgG1), BU33 (IgG1), BU35 (IgG2b) (Ling and Brown, 1992) and THB5 (Weis et al., 1984) were grown in serum-free hybridoma medium (Invitrogen) at $37{ }^{\circ} \mathrm{C}$ in $7.5 \% \mathrm{CO}_{2}$. Density gradient markers with known sedimentation coefficients were purchased from Sigma (Taufkirchen, Germany).

\subsection{Affinity chromatography}

Antibodies were affinity-purified using Protein-G Sepharose columns, dialyzed against PBS and 
coupled to NHS-Sepharose beads at a concentration of $2 \mathrm{mg} \mathrm{mAb} / \mathrm{ml}$ of column-material according to the manufacturer's instructions (AP Biotech, Freiburg, Germany). The beads were washed with $100 \mathrm{mM}$ Tris; $0.9 \% \mathrm{NaCl} ; 0.05 \%$ Tween 20 (TBST).

About $200 \mathrm{ml}$ of human plasma were filtered through a filter paper, centrifuged at 40,000 rpm in an SW40 swing out rotor (Beckman Instruments, Fullerton, USA) for $30 \mathrm{~min}$ at $4{ }^{\circ} \mathrm{C}$. The top lipid layer and the pellet were discarded. The cleared plasma was incubated with the antibody-coupled beads at $4{ }^{\circ} \mathrm{C}$ overnight on a roller. The beads were loaded into a column, washed with 10 column volumes of TBST (washing buffer-1) and another 10 column volumes of $20 \mathrm{mM}$ sodium citrate buffer $\mathrm{pH}$ 6.4 (washing buffer-2). The column was eluted in $500-\mu 1$ fractions with high salt, low $\mathrm{pH}$ elution buffer, $100 \mathrm{mM}$ sodium citrate, $\mathrm{pH} 3.0$ and the eluate neutralized with $200 \mu \mathrm{l}$ of $1 \mathrm{M}$ Tris $\mathrm{pH} 8.5$ (neutralizing buffer). Absorbance values were measured at 280 $\mathrm{nm}$ and samples of high absorbance were pooled. The samples were analyzed by SDS-PAGE and immunoblotting. The yield at this stage was around $1 \mathrm{mg}$ total protein.

\subsection{Density gradient centrifugation}

A semi-discontinuous density gradient of $5-50 \%$ glycerol was prepared. Briefly, different concentrations of glycerol were prepared in $50 \mathrm{mM}$ HEPES, 5 $\mathrm{mM} \mathrm{NaCl}, \mathrm{pH}$ 7.0. One milliliter of each glycerol solution was placed carefully one above the other with a broad tip-pipette starting from $50 \%$ glycerol at the bottom. Starting from the $50 \%$ layer, the next layers were diluted by a factor of 0.8 until the $5 \%$ layer. Around $500 \mu \mathrm{l}$ of the affinity-purified sCD21 were added to the top of the gradient and centrifuged at $40,000 \mathrm{rpm}$ in an SW40 swing out rotor (Beckman Instruments) for $24 \mathrm{~h}$. This permitted fine separation of the proteins from the affinity column purification. A similar gradient with density gradient marker proteins was run simultaneously to calculate the sedimentation coefficient of the sample. After centrifugation, the bottom of the tube was punctured with a needle and $500 \mu \mathrm{l}$ fractions were collected. About $10 \mu \mathrm{l}$ of each fraction were analyzed by SDS-PAGE and immunoblotting. The total yield of pure SCD21 was around $75-100 \mu \mathrm{g}$.

\subsection{Partial specific volume and frictional ratio}

The partial specific volume of sCD21 was calculated from the sequence of the extracellular portion of CD21 (Acc.No. PL0009) (Weis et al., 1986) using the method of Lee and Timasheff (1974). Constants for the carbohydrate moieties were taken from Gibbons (1966). The frictional ratio was calculated from the diffusion coefficient, molecular weight and partial specific volume (Bloomfield et al., 1967; Ackers, 1975).

\subsection{SDS-PAGE and immunoblotting}

The protein samples were run on a $10 \%$ polyacrylamide gel under reducing and nonreducing conditions, either stained with silver nitrate or electrophoretically transferred to nitrocellulose. The membranes were blocked with 5\% milk powder, washed with TBST and probed with monoclonal anti-CD21 antibody BU32. After three washes, the protein band was visualized with goat anti-mouse IgG coupled to horseradish peroxidase followed by Super signal chemiluminescent substrate (Perbio Science, Bonn, Germany).

\section{Results}

\subsection{Affinity purification of soluble CD21 from human plasma}

Clear human plasma was subjected to affinity chromatography with anti-CD21 antibodies coupled to sepharose as illustrated in Fig. 1. The antibodies used and their corresponding epitopes in $\mathrm{CD} 21$ were: THB5: SCR 3-4, BU32: SCR 8-9, BU35: SCR 5-6 (Ling et al., 1994). The eluate was subjected to a $10 \%$ gradient SDS-PAGE under reducing conditions (Fig. 2A). A band of about $126 \mathrm{kDa}$ was seen following to immunoblotting and probing with anti-CD21 antibody clone BU32 (data not shown). However, silver staining revealed several additional bands.

In order to separate sCD21 from co-purified or contaminating proteins, density gradient centrifugation of the eluate on a semi-discontinuous glycerol gradient was performed. This method resolves the proteins according to buoyant density and shape. Fractions were collected from the bottom of the tube, subjected to two parallel SDS-PAGE separations and either silver- 


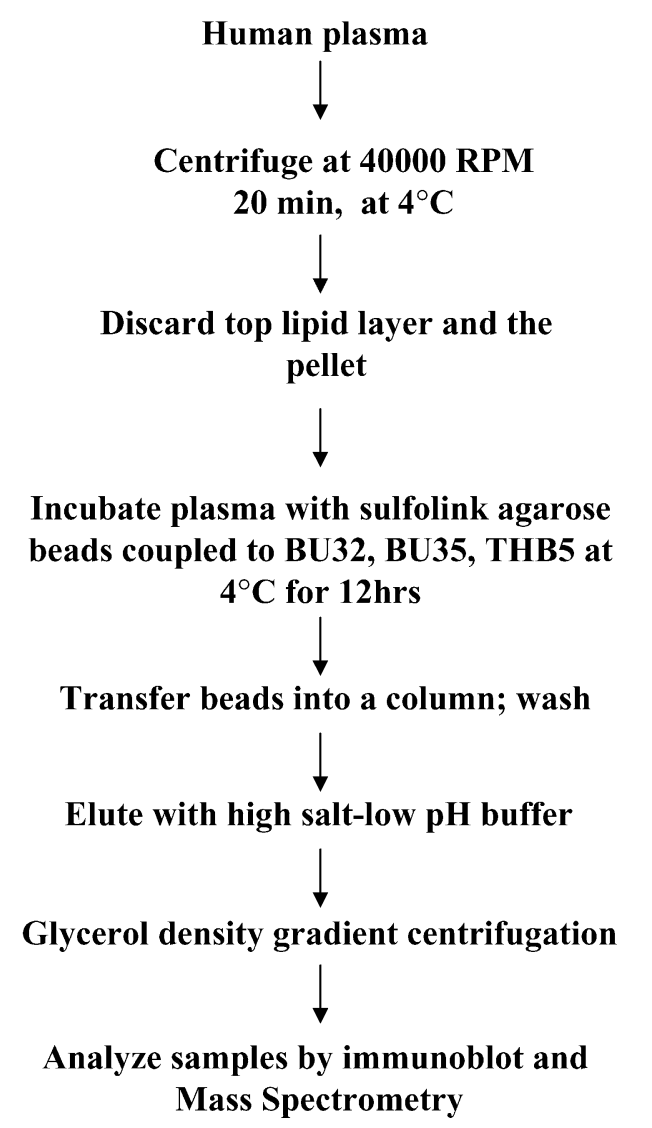

Fig. 1. Scheme of purification of soluble CD21 from human plasma.

stained (Fig. 2B) or blotted and probed with BU32 (Fig. $2 \mathrm{C}) . \mathrm{sCD} 21$ protein localized itself in fractions $16-18$ of the density gradient corresponding to a molecular weight of $126 \mathrm{kDa}$. No other band was detected in those fractions by silver staining. An aliquot of the protein was subjected to mass spectrometry-peptide analysis confirming the protein as CD21 (data not shown).

\subsection{Determination of the sedimentation coefficient of soluble CD21}

In order to investigate the biophysical nature of the protein, we determined the sedimentation coefficient of $\mathrm{SCD} 21$ in serum using density gradient markers of known Svedberg value $(S)$. Apoferritin (17.6 S), $\beta$ amylase $(8.9 \mathrm{~S})$ and bovine serum albumin $(4.2 \mathrm{~S})$ were used as markers and subjected to similar density gradients and run parallel along with sCD21. The fractions from marker gradients were subjected to dot blotting, stained with coomassie-brilliant blue and the mean fraction numbers in which the proteins localized were determined. The $S$ value of $\mathrm{sCD} 21$ was derived
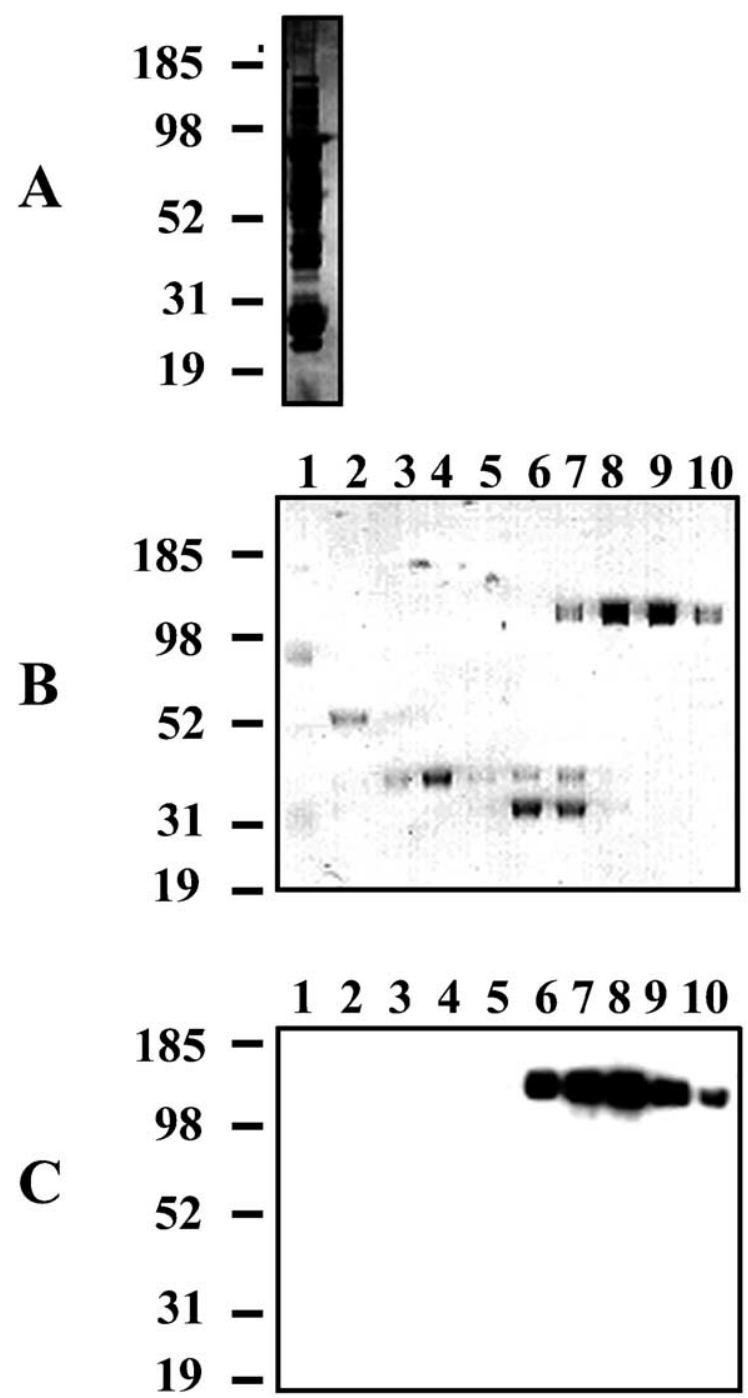

Fig. 2. Purity of sCD21. (A) $10 \mu \mathrm{l}$ of eluate from the affinity chromatography step were subjected to $10 \%$ polyacrylamide SDS PAGE under reducing conditions and stained with silvernitrate. (B) Alternate fractions from the density gradient centrifugation were run on a reducing $10 \%$ polyacrylamide gel and stained with silvernitrate. Lanes 1 to 10 , fractions 2 to 20 respectively. (C) Immunoblot of density gradient of samples as in (B), probed with anti-CD21, mAB BU32. Lanes 6-10; fractions 12, 14, 16, 18, 20, respectively. The $\mathrm{CD} 21$ protein was localized to fractions $16-18$. 


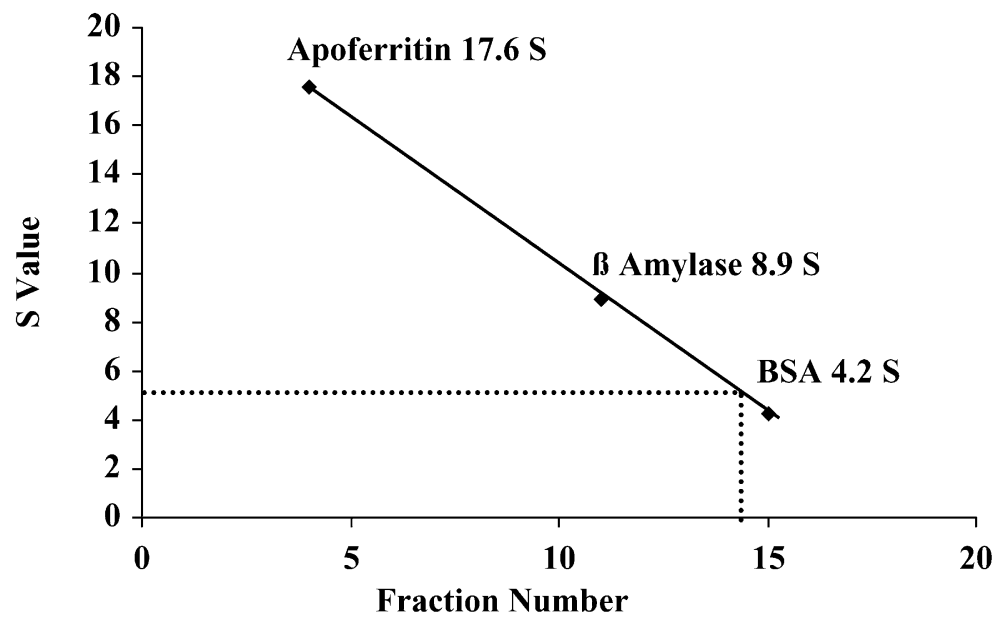

$50 \%$ Glycerol $\longrightarrow 5 \%$ Glycerol

Fig. 3. Sedimentation coefficient of CD21. The sedimentation coefficient of sCD21 was calculated by plotting a standard graph with marker proteins with known $S$ values. The values shown here are representative of three independent runs. The sCD21 protein was localized to fractions $13-15$ in this experiment, corresponding to an $S$ value of 5.2.

by plotting $S$ values against the fraction numbers of the markers and extrapolating the graph for $\mathrm{sCD} 21$ (Fig. 3). The $S$ value of sCD21 was found to be $5.2 \mathrm{~S}$.

\subsection{Hydrodynamic properties of $s C D 21$}

The physical properties of sCD21 were calculated from the sequence assuming that the extracellular portion of the protein is shed using the Einstein relation, Svedberg equation and Stoke's law (Ackers, 1975). The results of these calculations are shown in Table 1. The percentage of carbohydrate was calculated from the difference in molecular weight in SDS-PAGE compared to the predicted molecular weight of the apoprotein. Partial specific volume was found to be $0.70 \mathrm{~cm}^{3}$ / $\mathrm{g}$, calculated by the method of Lee and Timasheff (1974). The partial specific volume of the protein was corrected for carbohydrates on the basis of the average partial specific volumes of common sugar moieties

Table 1

Physical properties of $\mathrm{SCD} 21$

Partial specific volume, $\left(\mathrm{cm}^{3} / \mathrm{g}\right)$

Sedimentation coefficient, $s_{20, \omega}(\mathrm{S})$

Diffusion coefficient, $D_{20, \omega}\left(\mathrm{cm}^{2} / \mathrm{s}\right)$

Frictional ratio, $f / f_{0}$
(Gibbons, 1966). The partial specific volume of the protein was found to be within the limits of $0.6950-$ 0.7049 when the percentage of sugar was $12 \pm 3 \%$ and the value was rounded to the second decimal. Since the mobility of the protein is also influenced by the structure, we presume the exact carbohydrate percentage was within the range of $12 \pm 3 \%$. The frictional coefficient $(f)$ and the frictional ratio $\left(f l f_{0}\right)$ were calculated using the Bloomfield equation (Bloomfield et al., 1967) and the diffusion coefficient $D_{20, w}$ using the StokesEinstein equation (Ackers, 1975). The diffusion coefficient of $3.35 \times 10^{-7} \mathrm{~cm}^{2} / \mathrm{s}$ and the frictional ratio of 1.94 suggests that the molecule is elongated and rodshaped.

\subsection{Mobility of soluble CD21 and cellular CD21 during electrophoresis}

In order to characterize the protein further, we have affinity-purified cellular CD21 from lymphoblastoid cell lines such as the T cell line Molt- 4 and B cell line Raji. Both Molt-4 T cells and Raji B cells exhibited a band of around $140 \mathrm{kDa}$ upon SDS-PAGE/immunoblot with BU32, while the CD21 from plasma was found to be of $126 \mathrm{kDa}$ under reducing conditions. When we analyzed the same CD21 proteins under nonreducing conditions, we found an increase in 
mobility to $130 \mathrm{kDa}$ for the cellular CD21 and 120 $\mathrm{kDa}$ for the plasma-derived CD21. No other molecule (e.g. CD23) was associated with CD21 under our purification conditions. This contrasts to the previous report where purification of CD21 from sera revealed a smear of 130-190 kDa under nonreducing conditions. However, in our protocol, a glycerol density gradient centrifugation step was added after the affinity purification.

\section{Discussion}

Several membrane molecules are cleaved from the cell surface by endogenous cellular enzymes, releasing their soluble fragments into the extracellular medium and exerting their physiological functions in vivo (Bazil, 1995). Several reports have defined the functions of sCD21. Recombinant soluble CD21 has been shown to interfere with the attachment of EBV to B cells (Nemerow et al., 1990; Moore et al., 1991). Administration of a soluble CD21-IgG chimera suppressed antibody responses to $\mathrm{T}$ cell-dependent antigens in mice (Hebell et al., 1991), suggesting an immunomodulatory function of $\mathrm{sCD} 21$ in vivo. In addition to binding to iC $3 \mathrm{~b}, \mathrm{sCD} 21$ complexes with CD23 and inhibits sCD23-induced IgE synthesis by B cells (Fremeaux-Bacchi et al., 1998b). sCD21 induces activation and differentiation of human monocytes through binding to membrane-associated CD23, activating nitric oxide synthase (NOS) (Fremeaux-Bacchi et al., 1998a). CD21 also has functions which are unrelated to complement/EBV binding such as being a receptor for interferon- $\alpha$ (Delcayre et al., 1991). Elevated amounts of sCD21 are found in patients with B cell chronic lymphocytic leukemia, and the sCD21 levels are correlated with the surface expression of CD21 on the leukemic cells and the number of cells in the blood (Lowe et al., 1989). Although B cells are thought to be a major source of sCD21 in plasma, alternative sources, such as T cells and FDCs, may also contribute to the serum pool. This probably explains why concentrations of $\mathrm{sCD} 21$ in the serum of patients with hypo-gammaglobulinemia do not differ significantly from those of normal individuals (Ling et al., 1991). It is also of interest that there is a reduced expression of CD21 in synovial B and T cells in rheumatic patients, suggesting a role in autoim- munity (Illges et al., 2000) and the need to investigate whether changes in serum levels of sCD21 influence immunoregulation.

Even though $\mathrm{sCD} 21$ is known to exist as a complex with sCD23 in the circulation (Fremeaux-Bacchi et al., 1998b), density gradient centrifugation separates almost all the proteins that co-purify during the affinity chromatography step. Though there are reported to be several forms of $\mathrm{sCD} 21$ in the circulation (Ling and Brown, 1992), our method of density gradient centrifugation purifies a single species of 126 $\mathrm{kDa}$. Since we could not identify any other form of the protein by immunoblotting, we suggest that the 126$\mathrm{kDa}$ form of $\mathrm{sCD} 21$ is the predominant form in the circulation. We cannot rule out the possibility that the lower molecular weight forms of sCD21 previously reported could be degradation products of full-length CD21. Such putative degradation products might not contain the epitopes recognized by the monoclonal antibodies used. We have shown that the soluble form of CD21 exists as monomer and is not covalently linked to any other protein. This finding is in accordance with previous reports that the interactions of

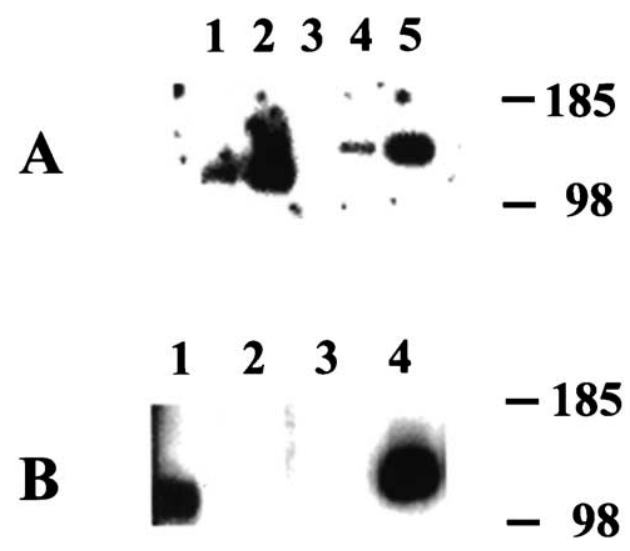

Fig. 4. Mobility of CD21 during polyacrylamide gel electrophoresis. (A) Cellular CD21 isolated by affinity chromatography from Molt-4 and Raji cell lines was subjected to $10 \%$ polyacrylamide gel electrophoresis, transferred to nitrocellulose and probed with BU32. Lane 1 and Lane 4: Molt-4 CD21 nonreduced and reduced, respectively, Lane 2 and Lane 5: Raji CD21 nonreduced and reduced, respectively. (B) Immunoblot with BU32 of soluble CD21 run under nonreducing (Lane 1), and reducing (Lane 4) conditions. CD21 runs faster under nonreducing conditions than under reducing conditions. Lanes 2 and 3 were loaded only with SDS sample loading buffer to prevent diffusion of the reducing agent between the lanes. 
sCD21 with its binding partners in serum are mainly through lectin interactions with linked oligosaccharides instead of protein-protein interaction (Aubry et al., 1994). We determined the sedimentation coefficient of sCD21 by density gradient centrifugation. The sedimentation coefficient of a protein depends on its molecular weight and shape and provides some clues regarding the conformation of the protein. The $S$ value of $\mathrm{sCD} 21$ was found to be 5.2, which is relatively low for a protein of $126 \mathrm{kDa}$. Calculations based on such hydrodynamic properties as the diffusion coefficient $\left(D_{20, \mathrm{w}}\right)$ and frictional ratio $\left(f / f_{0}\right)$ of sCD21 show that sCD21 is a rod-shaped molecule. Previous studies on these properties were reported by Moore et al. (1989) using a recombinant form of CD21 which comprised the extracellular portion expressed in a baculovirus expression system. The variations we found in the values compared to the published hydrodynamic properties may be explained by the different glycosylation patterns associated with the expression system used.

The native CD21 molecule consists of 15 or 16 short consensus repeats (SCRs) and is extensively Nglycosylated. The beads-on-string structure of the molecule may provide a complex secondary structure that retards the movement in a centrifugal field. This structure may also account for the anomalous high apparent molecular weight of $320 \mathrm{kDa}$ in gel filtration as reported by Ling et al. (1991). SDS-PAGE/ immunoblotting of both cellular and soluble CD21 with BU32 under nonreducing conditions shows an increased mobility of CD21 in contrast to the 135$190 \mathrm{kDa}$ smear of serum CD21 as reported by Fremeaux-Bacchi et al. (1998b). Our results (Fig. 4) show that the density gradient purified protein is not associated covalently (at least not through intermolecular disulfide bonds) with any other molecule and the resulting faster mobility upon boiling with a reducing agent is explained by breakdown of intramolecular disulfide bonds giving rise to a single polypeptide chain. This finding also emphasizes the fact that the native CD21 in serum may not be in circulation as a complex protein but exists as a monomer.

The method reported here enables us to purify sCD21 to homogeneity from human plasma and will permit further biochemical characterization of the protein.

\section{Acknowledgements}

We would like to thank Rolf Knippers and Ulrich Strausfeld for discussions during this work and for critical reading of the manuscript. The sera and plasma were kindly provided by Dr. Michael Schlesier. This work was supported by BMBF grant 01GG9834 and the Hans-Hench-Stiftung to HI.

\section{References}

Ackers, G.K., 1975. Molecular sieve methods of analysis. In: Neurath, H., Hill, R., Boeder, C.-L. (Eds.), The Proteins. Academic Press, London, pp. 1-94.

Ahearn, J.M., Fearon, D.T., 1989. Structure and function of the complement receptors, CR1 (CD35) and CR2 (CD21). Adv. Immunol. 46, 183-219.

Aubry, J.P., Pochon, S., Gauchat, J.F., Nueda-Marin, A., Holers, V.M., Graber, P., Siegfried, C., Bonnefoy, J.Y., 1994. CD23 interacts with a new functional extracytoplasmic domain involving $\mathrm{N}$-linked oligosaccharides on CD21. J. Immunol. 152, 5806-5813.

Bazil, V., 1995. Physiological enzymatic cleavage of leukocyte membrane molecules. Immunol. Today 16, 135-140.

Bloomfield, V., Dalton, W.O., Van Holde, K.E., 1967. Frictional coefficients of multisubunit structures: I. Theory. Biopolymers $5,135-148$.

Cherukuri, A., Cheng, P.C., Sohn, H.W., Pierce, S.K., 2001. The CD19/CD21 complex functions to prolong B cell antigen receptor signaling from lipid rafts. Immunity 14, 169-179.

Delcayre, A.X., Salas, F., Mathur, S., Kovats, K., Lotz, M., Lernhardt, W., 1991. Epstein Barr virus/complement C3d receptor is an interferon alpha receptor. EMBO J. 10, 919-926.

Delibrias, C.C., Fischer, E., Bismuth, G., Kazatchkine, M.D., 1992. Expression, molecular association, and functions of $\mathrm{C} 3$ complement receptors CR1 (CD35) and CR2 (CD21) on the human T cell line HPB-ALL. J. Immunol. 149, 768-774.

Dempsey, P.W., Allison, M.E., Akkaraju, S., Goodnow, C.C., Fearon, D.T., 1996. C3d of complement as a molecular adjuvant: bridging innate and acquired immunity. Science 271, $348-350$.

Fearon, D.T., 2000. Innate immunity—beginning to fulfill its promise? Nat. Immunol. 1, 102-103.

Fischer, E., Delibrias, C., Kazatchkine, M.D., 1991. Expression of $\mathrm{CR} 2$ (the $\mathrm{C} 3 \mathrm{dg} / \mathrm{EBV}$ receptor, $\mathrm{CD} 21$ ) on normal human peripheral blood T lymphocytes. J. Immunol. 146, 865-869.

Fischer, E.M., Mouhoub, A., Maillet, F., Fremeaux-Bacchi, V., Krief, C., Gould, H., Berrih-Aknin, S., Kazatchkine, M.D., 1999. Expression of CD21 is developmentally regulated during thymic maturation of human T lymphocytes. Int. Immunol. 11, $1841-1849$.

Fremeaux-Bacchi, V., Aubry, J.P., Bonnefoy, J.Y., Kazatchkine, M.D., Kolb, J.P., Fischer, E.M., 1998a. Soluble CD21 induces activation and differentiation of human monocytes 
through binding to membrane CD23. Eur. J. Immunol. 28, $4268-4274$.

Fremeaux-Bacchi, V., Fischer, E., Lecoanet-Henchoz, S., Mani, J.C., Bonnefoy, J.Y., Kazatchkine, M.D., 1998b. Soluble CD21 (sCD21) forms biologically active complexes with CD23: sCD21 is present in normal plasma as a complex with trimeric CD23 and inhibits soluble CD23-induced IgE synthesis by B cells. Int. Immunol. 10, 1459-1466.

Gibbons, R.A., 1966. Physico-chemical methods for the determination of the purity, molecular size and shape of glycoproteins. In: Gottschalk, A. (Ed.), Glycoproteins. Elsevier, Amsterdam, pp. 31-140.

Hebell, T., Ahearn, J.M., Fearon, D.T., 1991. Suppression of the immune response by a soluble complement receptor of B lymphocytes. Science 254, 102-105.

Huemer, H.P., Larcher, C., Prodinger, W.M., Petzer, A.L., Mitterer, M., Falser, N., 1993. Determination of soluble CD21 as a parameter of B cell activation. Clin. Exp. Immunol. 93, 195-199.

Iida, K., Nadler, L., Nussenzweig, V., 1983. Identification of the membrane receptor for the complement fragment C3d by means of a monoclonal antibody. J. Exp. Med. 158, 1021-1033.

Illges, H., Braun, M., Peter, H.H., Melchers, I., 2000. Reduced expression of the complement receptor type 2 (CR2, CD21) by synovial fluid $\mathrm{B}$ and $\mathrm{T}$ lymphocytes. Clin. Exp. Immunol. $122,270-276$.

Klein, G., Giovanella, B., Westman, A., Stehlin, J.S., Mumford, D., 1975. An EBV-genome-negative cell line established from an American Burkitt lymphoma; receptor characteristics. EBV infectibility and permanent conversion into EBV-positive sublines by in vitro infection. Intervirology $5,319-334$.

Larcher, C., Schulz, T.F., Hofbauer, J., Hengster, P., Romani, N., Wachter, H., Dierich, M.P., 1990. Expression of the C3d/EBV receptor and of other cell membrane surface markers is altered upon HIV-1 infection of myeloid, T, and B cells. J. Acquir. Immune Defic. Syndr. 3, 103-108.

Lee, J.C., Timasheff, S.N., 1974. The calculation of partial specific volumes of proteins in guanidine hydrochloride. Arch. Biochem. Biophys. 165, 268-273.

Ling, N.R., Brown, B., 1992. Properties of soluble CR2 in human serum. Immunobiology 185, 403-414.

Ling, N., Hansel, T., Richardson, P., Brown, B., 1991. Cellular origins of serum complement receptor type 2 in normal individuals and in hypogammaglobulinaemia. Clin. Exp. Immunol. 84, 16-22.

Ling, N.R., Brown, B., Hardie, D., 1994. Synergy test for recognition of epitopes on soluble proteins; its application in the study of $\mathrm{CD} 21$ and $\mathrm{CD} 23$ antigens and their respective antibodies. J. Immunol. Methods 173, 11-17.
Lowe, J., Brown, B., Hardie, D., Richardson, P., Ling, N., 1989. Soluble forms of CD21 and CD23 antigens in the serum in B cell chronic lymphocytic leukaemia. Immunol. Lett. 20, $103-109$.

Minowada, J., Onuma, T., Moore, G.E., 1972. Rosette-forming human lymphoid cell lines: I. Establishment and evidence for origin of thymus-derived lymphocytes. J. Natl. Cancer Inst. 49, 891-895.

Moore, M.D., DiScipio, R.G., Cooper, N.R., Nemerow, G.R., 1989. Hydrodynamic, electron microscopic, and ligand-binding analysis of the Epstein-Barr virus/C3dg receptor (CR2). J. Biol. Chem. 264, 20576-20582.

Moore, M.D., Cannon, M.J., Sewall, A., Finlayson, M., Okimoto, M., Nemerow, G.R., 1991. Inhibition of Epstein-Barr virus infection in vitro and in vivo by soluble CR2 (CD21) containing two short consensus repeats. J. Virol. 65, 3559-3565.

Myones, B.L., Ross, G.D., 1987. Identification of a spontaneously shed fragment of B cell complement receptor type two (CR2) containing the C3d-binding site. Complement 4, 87-98.

Nemerow, G.R., Mullen III, J.J., Dickson, P.W., Cooper, N.R. 1990. Soluble recombinant CR2 (CD21) inhibits Epstein-Barr virus infection. J. Virol. 64, 1348-1352.

Schwab, J., Illges, H., 2001a. Regulation of CD21 expression by DNA methylation and histone deacetylation. Int. Immunol. 13, $705-710$.

Schwab, J., Illges, H., 2001b. Silencing of CD21 expression in synovial lymphocytes is independent of methylation of the CD21 promoter CpG island. Rheumatol. Int. 20, 133-137.

Tedder, T.F., Clement, L.T., Cooper, M.D., 1984. Expression of C3d receptors during human $\mathrm{B}$ cell differentiation: immunofluorescence analysis with the HB-5 monoclonal antibody. J. Immunol. 133, 678-683.

Tsoukas, C.D., Lambris, J.D., 1993. Expression of EBV/C3d receptors on T cells: biological significance. Immunol. Today 14 , $56-59$.

Weis, J.J., Tedder, T.F., Fearon, D.T., 1984. Identification of a $145,000 \mathrm{Mr}$ membrane protein as the C3d receptor (CR2) of human B lymphocytes. Proc. Natl. Acad. Sci. U. S. A. 81, $881-885$.

Weis, J.J., Fearon, D.T., Klickstein, L.B., Wong, W.W., Richards, S.A., de Bruyn Kops, A., Smith, J.A., Weis, J.H., 1986. Identification of a partial cDNA clone for the $\mathrm{C} 3 \mathrm{~d} /$ Epstein-Barr virus receptor of human $\mathrm{B}$ lymphocytes: homology with the receptor for fragments $\mathrm{C} 3 \mathrm{~b}$ and $\mathrm{C} 4 \mathrm{~b}$ of the third and fourth components of complement. Proc. Natl. Acad. Sci. U. S. A. 83, 5639-5643. 